ISSN 2525-4812 (versão online)

ISSN 2238-7641 (versão impressa)

http://www.revistaterceiramargem.com/

index.php/terceiramargem/index
Recebido em: 31/5/2020

Aprovado para Sober 2020: 23/7/2020

Aceito para RTMA: 20/4/2021

Período de publicação: jan./jul. 2021
Revista Terceira Margem Amazônia

(v. $7 \cdot$ n. $17 \cdot$ Jan./Jun. 2021)

Como citar o artigo:

MORAES, A. J. G. de; SILVA, E. A.; ALMEIDA, E. N. de; MARIA, B. G. Análise de desempenho socioambiental da pecuária leiteira familiar na fazenda riacho grande, município de Bom Jesus do Tocantins, estado do Pará. Revista Terceira Margem Amazônia, v. 7, n. 17, p. 139-154, 2021. DOI: http://dx.doi.org/10.36882/2525-4812.2021v7i17.p139-154

\title{
ANÁLISE DE DESEMPENHO SOCIOAMBIENTAL DA PECUÁRIA LEITEIRA FAMILIAR NA FAZENDA RIACHO GRANDE, MUNICÍPIO DE BOM JESUS DO TOCANTINS, ESTADO DO PARÁ
}

\author{
Aldecy José Garcia de Moraes ${ }^{1}$ \\ Enilson Solano Albuquerque Silva ${ }^{2}$ \\ Everaldo Nascimento de Almeida ${ }^{3}$ \\ Bruno Giovany de Maria
}

\begin{abstract}
Resumo: O objetivo deste estudo foi avaliar o desempenho socioambiental da pecuária leiteira na agricultura familiar, em Unidade de Aprendizagem Tecnológica, conforme o contexto de adoção observado na Fazenda Riacho Grande, no município de Bom Jesus do Tocantins, estado do Pará. Como abordagem metodológica utilizou-se o sistema de "Avaliação de impactos de inovações tecnológicas agropecuárias", Ambitec-Agro, que consiste em módulos integrados de indicadores socioambientais para os setores produtivos rurais da agricultura, da produção animal e da agroindústria. O índice geral de desempenho das boas práticas tecnológicas relacionadas à pecuária de leite para agricultura familiar foi positivo, alcançando o valor de 3,55 (em uma escala de $-15 \mathrm{a}+15$ ). A maioria dos critérios analisados revelou efeitos positivos, destacando-se, na dimensão ecológica, a melhoria na qualidade do solo, a redução do uso de insumos veterinários e matérias-primas e de insumos agrícolas, contribuindo com a qualidade ambiental na propriedade. A exceção foram os critérios de consumo de água e energia, os quais tiveram efeitos negativos. $\mathrm{Na}$ dimensão de impactos socioambientais, os destaques foram a qualidade do produto e do bem-estar e saúde animal, a segurança alimentar e o incremento de renda no estabelecimento.
\end{abstract}

Palavras-chave: desempenho socioambiental, pecuária leiteira, agricultura familiar, ferramenta Ambitec-Agro.

\footnotetext{
1 Economista, mestre em Administração, analista da Embrapa Amazônia Oriental, Belém, PA.

E-mail: aldecy.moraes@embrapa.br

(D) https://orcid.org/0000-0002-8821-5879

2 Engenheiro-agrônomo, mestre em Agronomia, analista da Embrapa Amazônia Oriental, Belém, PA.

E-mail: enilson.solano@embrapa.br

(iD) https://orcid.org/0000-0003-4629-6129

3 Engenheiro-agrônomo, doutor em Desenvolvimento Sustentável do Trópico Úmido, pesquisador da Embrapa Amazônia Oriental, Belém, PA.

E-mail: everaldo.almeida@embrapa.br

(D) https://orcid.org/0000-0001-5523-3643

4 Zootecnista, mestre em Zootecnia, pesquisador da Embrapa Amazônia Oriental, Belém, PA.

E-mail: bruno.maria@embrapa.br

(D) https://orcid.org/0000-0001-7842-539X
} 


\title{
ANALYSIS OF THE SOCIAL AND ENVIRONMENTAL PERFORMANCE OF FAMILY DAIRY FARMING IN THE RIACHO GRANDE FARM, MUNICIPALITY OF BOM JESUS DO TOCANTINS, STATE OF PARÁ
}

\begin{abstract}
The objective of this study was to evaluate the socio-environmental performance of family dairy farming in a Technological Learning Unit, according to the context of adoption observed in the Riacho Grande Farm, in the municipality of Bom Jesus do Tocantins, state of Pará. As a methodological approach, we used the 'Evaluation of the impact of agricultural technological innovations' system - Ambitec-Agro, which consists of integrated modules of socio-environmental indicators for the rural productive sectors of agriculture, animal production and agro-industry. The General Performance Index of good technological practices related to family dairy farming was positive, reaching a value of 3.55 (on a scale of -15 to +15 ). Most of the criteria analyzed showed positive effects, with an emphasis on the ecological dimension, the improvement in soil quality, the reduction in the use of veterinary and raw materials, and agricultural inputs, contributing to the environmental quality of the property. The exception was the water and energy consumption criteria, which had negative effects. In the dimension of socio-environmental impacts, the highlights were product quality and animal welfare and health, food security and increased income in the establishment.
\end{abstract}

Keywords: social and environmental performance, dairy farming, family farming, Ambitec-Agro Tool.

\section{Introdução}

A atividade leiteira reveste-se de grande importância econômica para o estado do Pará, especialmente na mesorregião Sudeste, ao mesmo tempo depara-se com um quadro de intensas dificuldades e restrições para o seu desenvolvimento, sobretudo no âmbito tecnológico e de mercado.

O estado do Pará atualmente é o segundo maior produtor de leite da região Norte, com uma produção de mais de 600 milhões de litros/ano, suplantado apenas pelo estado de Rondônia, que detém mais da metade do volume produzido e é o líder da região. Do ponto de vista espacial, a mesorregião sudeste do Pará concentra mais de $70 \%$ da produção, e o município de Bom Jesus de Tocantins posiciona-se entre os dez maiores produtores de leite do estado, com produção na ordem de 18,9 milhões de litros/ano (IBGE, 2019a).

A pecuária de leite, nessa região do estado, é desenvolvida essencialmente por pequenos produtores familiares, em sistema extensivo e pouco especializado, em propriedades com baixo nível de utilização de tecnologias, estrutura física deficiente, manejo animal inadequado e pastagem degradada, características que conferem baixa produtividade aos sistemas produtivos da região (SENA et al., 2014; SOARES et al., 2014).

Ações de pesquisa e de transferência de tecnologia foram estabelecidas a partir de 2015 pelo Projeto Transferência de Tecnologias Apropriadas para a Promoção de Sistemas de Produção de Leite nas Propriedades Familiares do Sudeste Paraense, da Embrapa Amazônia Oriental, como forma de contribuir para a mudança desse cenário adverso. Uma das estratégias utilizadas foi a implantação de unidades de aprendizagem tecnológica (UATs), que serviriam como referência aos produtores da região no processo de transferência e adoção de tecnologia. A partir das boas práticas implementadas nas UATs, o propósito foi estabelecer um novo patamar tecnológico para 
a pecuária de leite, visando melhorar o desempenho produtivo, econômico e socioambiental dos estabelecimentos de pequenos produtores de leite da região.

Este estudo teve como objetivo avaliar o desempenho socioambiental da pecuária leiteira na agricultura familiar em UAT, conforme o contexto de adoção observado na Fazenda Riacho Grande, no município de Bom Jesus de Tocantins, estado do Pará.

\section{Considerações Metodológicas}

A presente análise de desempenho socioambiental da adoção de boas práticas tecnológicas relacionadas à pecuária leiteira para agricultura familiar foi realizada com base em um estudo de caso atinente à UAT Fazenda Riacho Grande, localizada no município de Bom Jesus de Tocantins, no Sudeste Paraense. O levantamento de dados para análise dos indicadores ocorreu durante visita a campo, realizada por membros da equipe do projeto nos dias 18 e 19 de setembro de 2018, com acompanhamento do proprietário da Fazenda Riacho Grande e sua esposa, a qual também participa das atividades do estabelecimento agrícola.

Como abordagem metodológica utilizou-se o sistema de avaliação de impactos de inovações tecnológicas agropecuárias, Ambitec-Agro, tal como disposto em Rodrigues (2015) e Rodrigues et al. (2003a, 2003b, 2010, 2018), que consiste em módulos integrados de indicadores socioambientais para os setores produtivos rurais da agricultura, da produção animal e da agroindústria. O sistema é composto de um conjunto de matrizes de ponderação multicritério, construídas para 148 indicadores, integrados em 27 critérios, distribuídos em 7 aspectos relacionados aos impactos resultantes do contexto de adoção tecnológica ou implementação de atividades rurais, para o desempenho socioambiental do estabelecimento, quais sejam: eficiência tecnológica e qualidade ambiental, na dimensão de impactos ecológicos; respeito ao consumidor, emprego, renda, saúde e gestão e administração, na dimensão de impactos socioambientais (Figura 1).

Figura 1. Dimensões e critérios considerados na verificação de campo para a avaliação de desempenho socioambiental de inovações tecnológicas e atividades rurais com o sistema Ambitec-Agro.

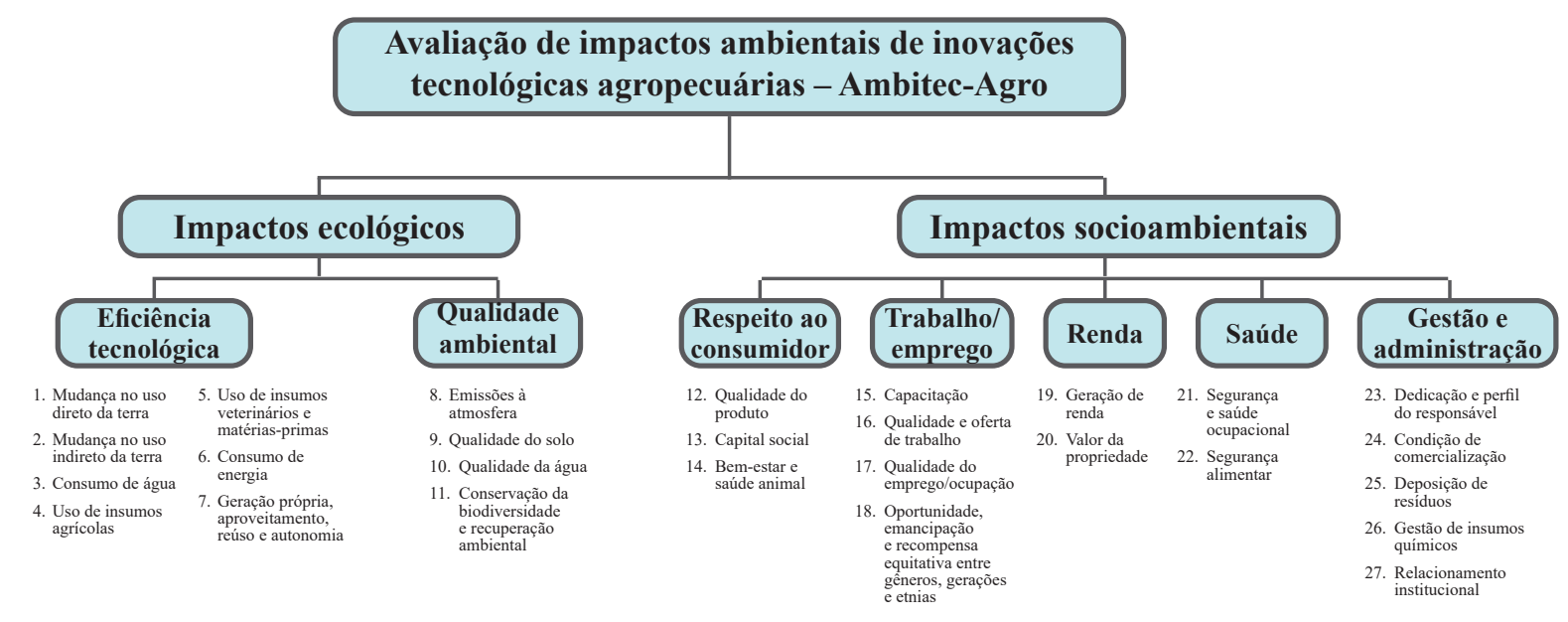

Fonte: Ambitec-Agro 
Durante os estudos de avaliação de impactos, o usuário do sistema e o produtor responsável indicam, conforme observações de campo e levantamento de dados históricos e de gestão do estabelecimento, os coeficientes de alteração dos indicadores, em razão específica da aplicação tecnológica e nas condições de manejo particulares à situação estudada, compondo assim cada produtor uma unidade amostral de avaliação de impacto. Esses coeficientes de alteração dos indicadores são definidos conforme a Tabela 1 .

Tabela 1. Impacto da inovação tecnológica (ou atividade rural), conforme contexto específico de adoção observado no estabelecimento rural, e coeficientes de alteração a serem inseridos nas matrizes de ponderação de indicadores Ambitec-Agro.

\begin{tabular}{|c|c|}
\hline $\begin{array}{l}\text { Impacto da tecnologia ou atividade rural observado sob as condições de manejo } \\
\text { específicas do estabelecimento }\end{array}$ & $\begin{array}{l}\text { Coeficiente de } \\
\text { alteração do indicador }\end{array}$ \\
\hline Grande aumento no indicador ( $>25 \%)$ & +3 \\
\hline Moderado aumento no indicador $(\leq 25 \%)$ & +1 \\
\hline Indicador inalterado & 0 \\
\hline Moderada diminuição no indicador $(\leq 25 \%)$ & -1 \\
\hline Grande diminuição no indicador ( $>25 \%)$ & -3 \\
\hline
\end{tabular}

As matrizes de ponderação do sistema Ambitec-Agro incluem ainda dois fatores de ponderação, que se referem à importância do indicador na composição dos critérios de impacto e à escala da ocorrência dos efeitos observados em campo. A ponderação da importância dos indicadores na composição do critério é uma etapa de normalização, devido aos diferentes números de indicadores que compõem os diversos critérios. Os valores de importância dos indicadores, expressos nessas matrizes, podem ser alterados pelos usuários do sistema para melhor refletir situações específicas de avaliação, e quando se pretende enfatizar (ou desconsiderar) alguns dos indicadores, desde que a soma dos valores de importância seja igual à unidade $(+/-1$, a depender da direção do impacto, se positivo ou negativo).

O fator de ponderação da escala de ocorrência, por sua vez, explicita o espaço no qual se observam os impactos da tecnologia ou atividade rural considerada, conforme a situação específica de adoção e contexto de manejo observado no estabelecimento rural, e pode ser:

1) pontual, quando o impacto se restringe ao campo cultivado, à instalação ou recinto de criação, ou à unidade produtiva agroindustrial na qual esteja ocorrendo a alteração no indicador; $\mathbf{O U}$

2) local, quando o impacto se estende para além do pontual, porém confinado aos limites do estabelecimento rural ou agroindustrial; OU AINDA

3) no entorno, quando o impacto observado extrapola os limites do estabelecimento rural ou agroindustrial, afetando áreas vizinhas.

O fator de ponderação da escala de ocorrência implica a multiplicação dos coeficientes de alteração dos indicadores por valores predeterminados, conforme apresentado na Tabela 2. 
Tabela 2. Fatores de ponderação multiplicativos, relativos à escala de ocorrência dos impactos sobre os indicadores de desempenho da atividade rural ou inovação tecnológica analisada.

Escala espacial de ocorrência dos impactos sobre os indicadores Fatores de ponderação

Pontual: campo cultivado ou recinto, $\mathrm{OU}$ 1

Local: o estabelecimento rural ou agroindustrial, $\mathrm{OU}$

Entorno: além dos limites do estabelecimento 5

Duas particularidades dos efeitos das tecnologias ou atividades rurais sobre os indicadores são incluídas nas matrizes de ponderação:

1) Primeiro, com o objetivo de diferenciar indicadores inalterados (aqueles com coeficiente de alteração igual a zero) daqueles que eventualmente não se apliquem ao caso em estudo, as matrizes de ponderação incluem uma linha para exclusão do indicador ("não se aplica"). Nesses casos, o usuário deverá zerar o fator de ponderação de importância do indicador excluído e redistribuir o valor para os outros indicadores, mantendo assim a escala final de expressão de resultados ( $+/-1$, a depender da direção do impacto).

2) Uma segunda característica de algumas das matrizes de ponderação é a restrição da escala de ocorrência somente em nível pontual, quando a influência do indicador é espacialmente restrita, e não faz sentido considerar outras escalas. Nesses casos, visando manter a consistência da escala de expressão de resultados, o fator de ponderação será sempre o máximo (5).

O procedimento de avaliação Ambitec-Agro consiste em verificar a direção (aumenta, diminui ou permanece inalterado) e a escala de ocorrência (pontual, local ou entorno) dos coeficientes de alteração dos indicadores para cada critério, atribuídos em razão específica da aplicação da tecnologia ou implementação da atividade rural, nas condições de manejo observadas em campo. Os resultados da avaliação de impacto são apresentados graficamente na planilha "Índices de impacto", expressos em escala de atribuição multicritério entre \pm 15 .

Assim, um estudo de avaliação de impactos com o método Ambitec-Agro se desenvolve em três etapas, a saber: 1) definição da magnitude de aplicação tecnológica ou atividade rural, delimitação geográfica da adoção e dos usuários, para seleção e contextualização da amostra; 2) vistoria de campo/levantamento de dados junto ao produtor, análise dos indicadores e preenchimento das matrizes de ponderação; e 3) avaliação dos índices de desempenho obtidos, interpretação e formulação de relatório individual ao produtor, com proposição de práticas alternativas de manejo e adoção tecnológica, visando minimizar impactos negativos e promover impactos positivos.

Durante os trabalhos de análise dos indicadores de desempenho socioambiental na Fazenda Riacho Grande, as bases metodológicas para a avaliação de impactos foram detalhadas e debatidas; apresentou-se ainda o contexto de adoção e particularidades do histórico de transição produtiva e de gestão, visando atribuir especificamente as alterações socioambientais resultantes da implantação e condução das boas práticas tecnológicas relacionadas à pecuária de leite no estabelecimento. O estudo teve por objetivo sistematizar a avaliação de impactos conforme o contexto 
produtivo observado no estabelecimento rural desde 2015, quando se iniciou na propriedade a transição da pecuária de leite com produção extensiva de baixa produtividade para o atual estágio como UAT em sistema sustentável de produção de leite no município e região.

\section{Resultados}

\section{Localização e características produtivas da UAT}

A Fazenda Riacho Grande situa-se nas coordenadas 56'6" latitude sul e 483' $58^{\prime \prime}$ longitude oeste (Figura 2), a cerca de 175 metros de altitude, no município de Bom Jesus de Tocantins, que está situado na mesorregião Sudeste do estado do Pará, com área total de 2.816,604 km², população estimada, no ano de 2020, em aproximadamente 17.118 habitantes e densidade demográfica de 5,43 hab./km² (IBGE, 2020). Em 2019, no município, a ocupação dos solos pela agropecuária era de 1,1 mil ha, principalmente com lavouras temporárias (1.060 ha), destacando-se o cultivo de mandioca (415 ha), milho (400 ha), arroz (160 ha) e feijão (85 ha) (IBGE, 2019b). As pastagens em boas condições ocupavam área de cerca de 92,4 mil hectares, sendo 5 mil hectares de pastagens degradadas e 6 mil hectares de pastos naturais, o que correspondia a aproximadamente $72 \%$ das áreas dos estabelecimentos rurais da época (143,4 mil hectares) (IBGE, 2017). O rebanho bovino era de 201.920 mil cabeças, 3.226 cabeças de equinos e 3.010 cabeças de ovinos. A produção de leite, em 2019, alcançou aproximadamente 18,9 milhões de litros, posicionando o município entre os dez maiores produtores do estado do Pará, atualmente com 605,1 milhões de litros (IBGE, 2019a). A área de silvicultura era de 1,1 mil hectare, concentrada em plantios de eucalipto (IBGE, 2019c).

Os usos da terra verificados na Fazenda Riacho Grande, que possui área total de 42,7 ha, envolvem, predominantemente, a pecuária de leite, com plantel de 70 vacas da raça Girolanda e 60 novilhas, além de uma pequena área com a exploração de açaizais de grota e de cultivo em terra firme. Inicialmente, a atividade com pecuária de leite caracterizava-se pela produção extensiva, com baixa capacidade de suporte da pastagem, baixa produtividade e infraestrutura inadequada.

A partir de 2015, com a implantação da UAT, foi introduzido um conjunto de práticas tecnológicas, tais como: reforma da pastagem com correção e adubação do solo e introdução dos capins mombaça (Megathyrsus maximus) e braquiária (Brachiaria brizantha); implantação do sistema de pastejo rotacionado, com cerca elétrica, e formação de capineira com cana-de-açúcar (Figura 3); utilização da técnica de inseminação artificial para melhorar o desempenho do rebanho. Em termos de infraestrutura foi construído um curral coberto, com piso pavimentado e brete; implantada a ordenha mecânica e instalado um resfriador fornecido pela empresa de laticínio Beatriz, com sede em Vila Nova dos Martírios, estado do Maranhão, visando à melhoria da qualidade do leite. 
Figura 2. Vista geral com os limites da área da Fazenda Riacho Grande e posição geográfica do município de Bom Jesus de Tocantins, no estado do Pará.

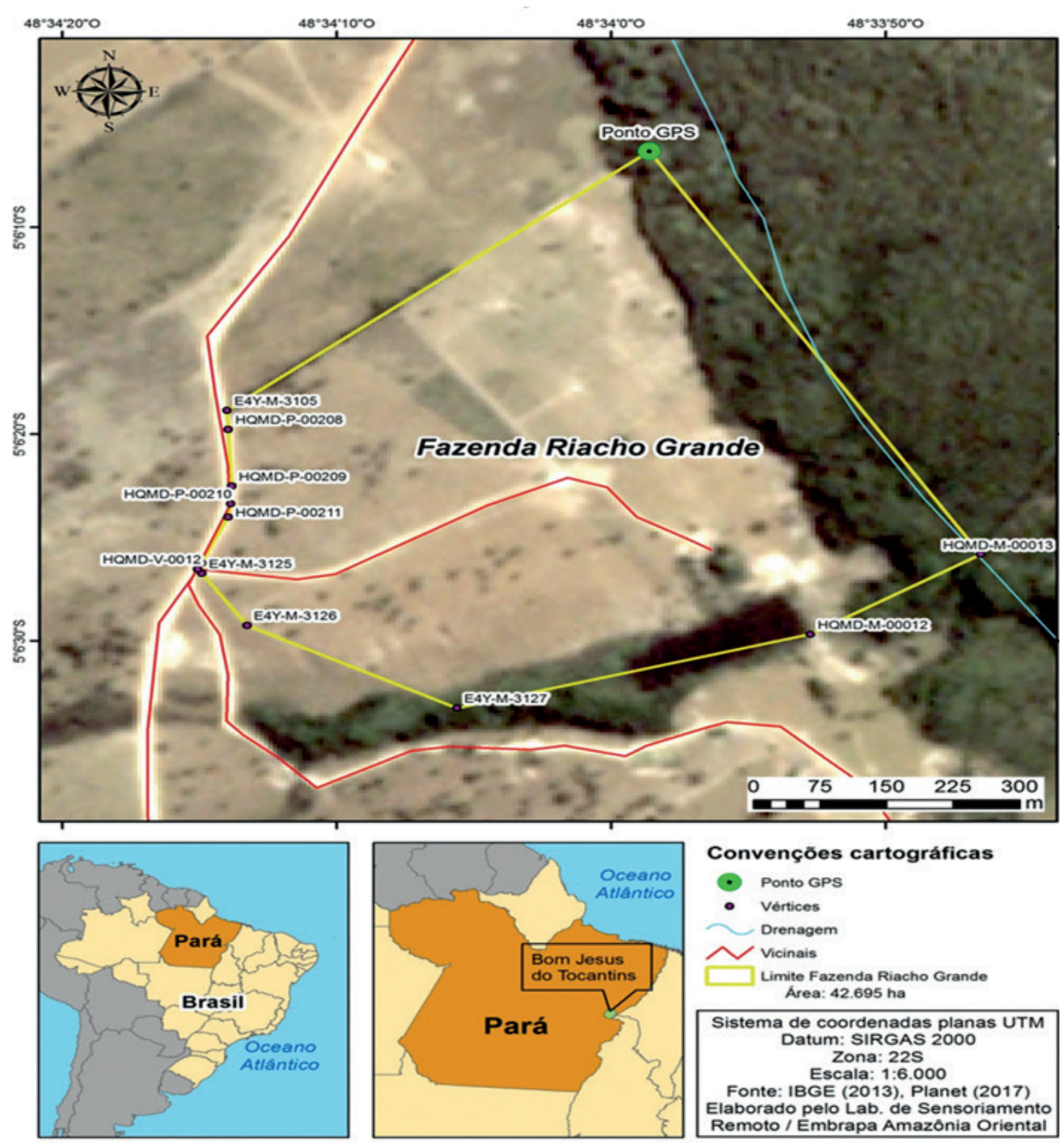

Fonte: Elaborado pelo Laboratório de Sensoriamento Remoto da Embrapa Amazônia Oriental com base em IBGE (2013); Pará (2017). 
Figura 3. (A) área de pastagem e ao fundo, à esquerda, capineira com cana-de-açúcar; (B) cerca elétrica na Fazenda Riacho Grande.
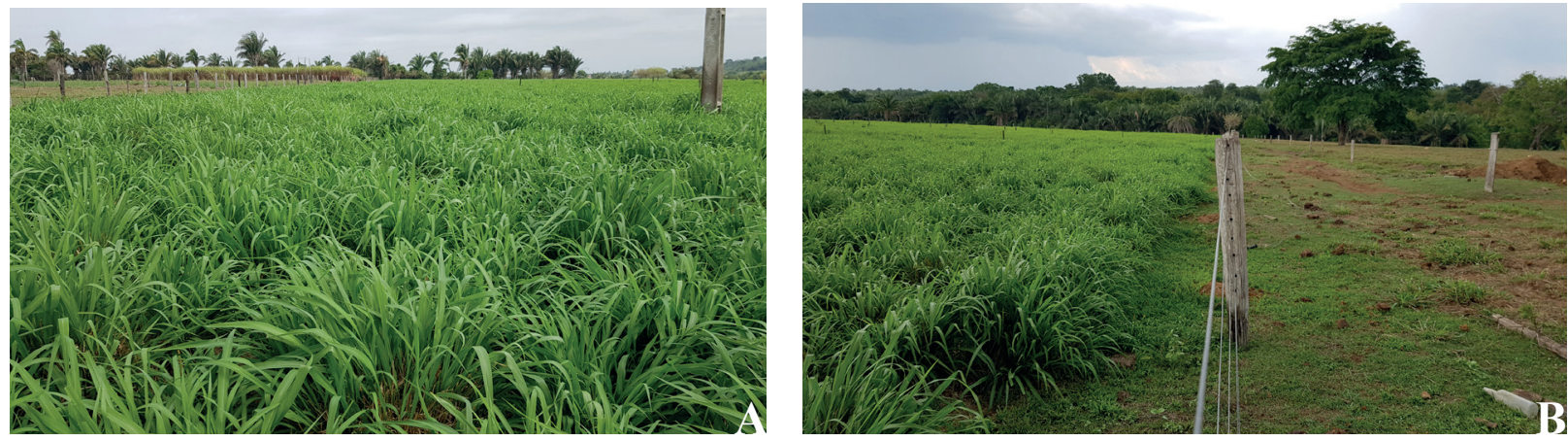

Fotos: Enilson Silva, 2018.

\section{Detalhamento do sistema de indicadores}

Os índices de desempenho socioambiental observados para os 27 critérios Ambitec-Agro, segundo o contexto de adoção do sistema de produção de leite na Fazenda Riacho Grande, são apresentados na Figura 4.

Figura 4. Coeficientes de desempenho socioambiental das boas práticas tecnológicas relacionadas à pecuária de leite para agricultura familiar, conforme contexto de adoção na Fazenda Riacho Grande (Bom Jesus do Tocantins, PA, setembro de 2018), obtidos a partir do Sistema de avaliação de impactos ambientais de inovações tecnológicas agropecuárias.

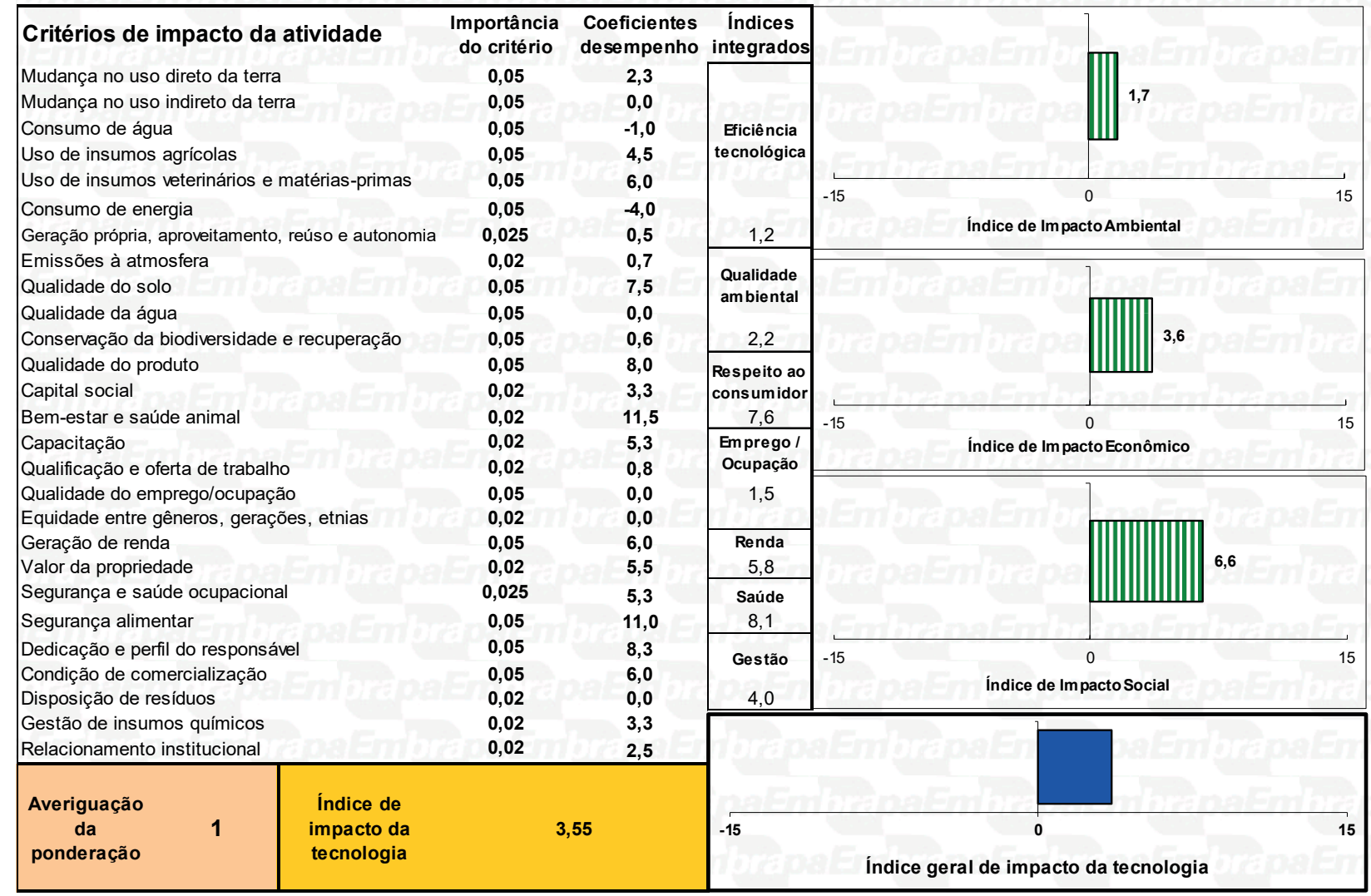

Fonte: Ambitec-Agro. 


\section{Dimensão impactos ecológicos}

Nessa dimensão são tratados os impactos das atividades produtivas sobre o ambiente, considerados em duas vertentes. A montante do processo produtivo se consideram as alterações nos usos da terra, a eficiência produtiva e o uso de insumos, recursos e energia; enquanto a jusante são considerados os efeitos da atividade sobre a qualidade do ambiente, seja devido à emissão de poluentes, seja quanto à conservação e recuperação de habitats naturais e áreas de conservação da biodiversidade. Dois aspectos são considerados com essa abrangência: "eficiência tecnológica", com sete critérios, e "qualidade ambiental", composto por quatro critérios, conforme Figura 4, acima.

A adoção de boas práticas tecnológicas por meio da reforma da pastagem, com correção e adubação do solo e a utilização dos capins mombaça e braquiária, bem como a implantação do sistema de pastejo rotacionado proporcionaram a intensificação produtiva da pecuária de leite da Fazenda Riacho Grande e favoreceram os indicadores de mudanças nos usos diretos da terra (índice $=2,3$ ), aumentando significativamente a produtividade por unidade de área (efeito poupa terra), decorrente da elevação da taxa de lotação da pastagem, passando de 1 unidade animal (UA)/ ha para $6 \mathrm{UA} / \mathrm{ha}$; aumento nos estoques de carbono no solo e na biomassa vegetal, resultante do maior rendimento da pastagem no sistema. Além disso, foram observadas melhorias no indicador relativo a risco de incêndios, em razão da resposta mais rápida de recuperação da pastagem pós-estiagem e maior controle do capim nos piquetes. Por sua vez, no tocante às mudanças no uso indireto da terra, não foram observadas alterações nos seus indicadores.

Os processos implantados e a melhoria da infraestrutura no estabelecimento geram reflexos nos padrões de consumo de água (índice $=-1,0$ ), com aumento do consumo comparativamente à situação anterior sem a adoção das boas práticas tecnológicas. Tal aumento decorre do uso além da disponibilidade temporária, utilizando-se maior volume de água para lavagem do curral, limpeza da ordenhadeira mecânica e do resfriador, implicando impactos ambientais moderadamente negativos nesse indicador. Contudo, devem-se relativizar esses efeitos, posto que, com a intensificação produtiva, constata-se um aumento da produtividade do leite em comparação ao aumento do consumo de água. Em relação ao comprometimento do uso da água por contaminação e captação e armazenamento, alterações não foram observadas. No tocante ao consumo de água para irrigação, prática recomendada para a melhoria do sistema, observa-se que não houve modificação, porque o produtor ainda não utiliza essa prática, embora haja pretensões futuras de uso na propriedade.

Importantes alterações foram observadas nos padrões de uso de insumos agrícolas (índice $=4,5$ ) para fins de controle de plantas daninhas e de fertilidade do solo, atribuídas à adoção das boas práticas tecnológicas na propriedade. A implantação do sistema do pastejo rotacionado em piquetes, o qual reduz o tamanho da área para o uso animal, além da utilização de forrageiras que permitem a melhor formação da pastagem, resulta em grande redução da frequência de aplicação de herbicidas no pasto. Em relação ao uso de fertilizantes, embora tenha ocorrido um aumento absoluto do uso de adubos químicos e calcário em decorrência do processo de intensificação produtiva com elevação da UA/ha na propriedade, observa-se uma redução relativa do uso por unidade de produto (leite), já que o aumento de volume deste foi muito maior. 
Os efeitos da intensificação produtiva também são observados em relação à diminuição do padrão de uso de insumos veterinários e matérias-primas (índice $=6,0$ ). O uso relativo de medicamentos diminuiu consideravelmente quando comparado ao padrão de tratamento anterior, em decorrência da melhor sanidade dos animais, ocasionada pela melhoria da qualidade nutricional e disponibilidade da pastagem. Esses fatores, aliados à introdução de forragem de cana-de açúcar na alimentação dos animais, refletiram na diminuição do uso de rações e suplementos, principalmente o consumo de sal. De outro lado, ocorre um aumento moderado do uso de certas matérias-primas, a exemplo de sabão neutro e produtos de limpeza, na execução de alguns procedimentos como a lavagem do curral e a higienização por ocasião da ordenha.

Em relação ao consumo de energia, houve alterações nos padrões de consumo (índice = $-4,0$ ), ocorrendo um crescimento em função das boas práticas tecnológicas adotadas, seja pelo uso de combustível para o transporte da cana-de-açúcar da capineira até o curral, seja pelo uso da eletricidade para a cerca elétrica dos piquetes, para a operacionalização da ordenhadeira mecânica e, principalmente, para o resfriador do leite. Embora tenha ocorrido um aumento no consumo de energia, em média de $250 \mathrm{KwH}$ (que atendia somente as instalações da casa/sede), para os atuais aproximados $900 \mathrm{KwH}$, deve-se relativizar esse aumento, dado o crescimento da produtividade e da qualidade do leite.

Importante mencionar que a intensificação produtiva e a melhoria da infraestrutura, com a instalação do curral na Fazenda Riacho Grande, permitiram maior concentração dos animais e, por conseguinte, maior disponibilidade e aproveitamento do esterco produzido, contribuindo para mais autonomia de insumos orgânicos na propriedade (índice $=0,5$ ). Esse insumo é destinado para a adubação nos cultivos de açaizeiro e cana-de-açúcar.

A adoção das boas práticas tecnológicas relacionadas à pecuária de leite para agricultura familiar, implantadas na propriedade, teve um balanço final positivo para o índice de desempenho no aspecto eficiência tecnológica (índice agregado $=1,2$ ), comparativamente ao contexto produtivo anterior, no qual era utilizado o sistema extensivo de produção de leite.

Em relação ao aspecto qualidade ambiental, verificam-se alterações parciais nos seus critérios, com reflexos positivos, ainda que moderados, no desempenho ambiental do estabelecimento (índice agregado $=2,2$ ). Para esse aspecto são considerados os critérios relativos à emissão de poluentes atmosféricos, qualidade do solo e da água, além de conservação da biodiversidade e recuperação ambiental. No tocante ao critério emissões à atmosfera (índice $=0,70$ ), as boas práticas tecnológicas utilizadas na propriedade permitem maior captura de gases de efeito estufa, em função do acúmulo de matéria orgânica na biomassa decorrente do melhor desempenho das pastagens, seja por meio da correção e adubação do solo, seja pela introdução das forrageiras. Por sua vez, em razão da operacionalização de alguns equipamentos, como o resfriador e a bomba hidráulica, ocorre a emissão moderada e pontual de ruídos. Em relação aos indicadores relacionados à emissão de fumaça e material particulado, bem como à geração de odores, não houve modificação.

Quanto ao critério qualidade do solo (índice $=7,5$ ), os efeitos positivos decorrentes da adoção das boas práticas tecnológicas na propriedade resultaram na melhoria de todos os seus indicadores. Os benefícios para o solo, proporcionados pela correção e adubação, além da introdução 
de forrageiras de melhor qualidade, tiveram reflexos no aumento da biomassa das pastagens e melhor cobertura e proteção do solo. Essas práticas favoreceram a redução da erosão, da perda de matéria orgânica e de nutrientes. Além disso, com a introdução do sistema de pastejo rotacionado, que reduz o tempo de permanência dos animais nos piquetes, consequentemente diminui o pisoteio deles no pasto, tendo como efeito a redução significativa da compactação do solo.

Em relação ao critério qualidade da água, as práticas tecnológicas adotadas não promoveram alterações nos seus indicadores. Menciona-se a existência de uma nascente e um riacho, que percorrem a propriedade e são protegidos por cerca de arame, além de mata ciliar, não ocorrendo assoreamento, exposição à contaminação nem carreamento de estercos e outros efluentes para esses corpos d'água. Referente ao critério conservação da biodiversidade e recuperação ambiental, efeitos moderadamente positivos são observados nos indicadores de recuperação ambiental (índice $=0,6$ ), especificamente na recuperação de solos e ecossistemas degradados, decorrentes das práticas de correção e adubação de solo e formação de pastagem de melhor qualidade.

\section{Dimensão impactos socioambientais}

Nessa dimensão são avaliados os impactos das boas práticas tecnológicas adotadas na pecuária de leite na qualidade de vida das pessoas envolvidas e na melhoria contínua dos processos produtivos e de gestão na Fazenda Riacho Grande. Cinco aspectos são considerados para essa dimensão: respeito ao consumidor, com três critérios; trabalho e emprego, com quatro critérios; renda, composto por dois critérios; saúde, com dois critérios; e gestão e administração, composto por cinco critérios, apresentados na Figura 1 (página 137).

$\mathrm{O}$ aspecto respeito ao consumidor apresentou coeficiente de desempenho positivo (índice $=$ 7,6), destacando-se os critérios referentes a bem-estar e saúde animal (índice $=11,5$ ) e à qualidade do produto (índice $=8,0$ ). As adequações da infraestrutura no estabelecimento, com a implantação do sistema de pastejo rotacionado em piquetes e pastagem de boa qualidade, bem como a introdução de capineira com cana-de-açúcar e a instalação de bebedouros, facilitam o acesso a água, alimentação e suplementação de melhor qualidade e permitem a lotação adequada no pasto, além disso o sombreamento por meio de sombrite favorece o conforto térmico e minimiza o sofrimento e estresse dos animais. Ressalta-se que o produtor iniciou o plantio de espécies arbóreas para melhorar ainda mais essas condições. A instalação do curral, com piso, cobertura e brete adequados, propicia maior segurança e manejo sanitário preventivo e salubridade aos ambientes de manejo. Todos esses procedimentos têm facilitado uma maior aproximação homem-animal, contribuindo assim para que os animais expressem comportamentos favoráveis ao manejo e consequentemente ao melhor desempenho das atividades realizadas. Dessa forma, as condições de bem-estar e saúde animal se apresentam superiores àquelas observadas no sistema anterior com a pecuária extensiva.

A qualidade do produto (leite) foi sensivelmente melhorada em decorrência das boas práticas adotadas no estabelecimento, as quais tiveram efeitos positivos nos seus indicadores. A formação de pastagem de melhor qualidade, decorrente, dentre outros fatores, da menor utilização de defensivos químicos no pasto, favorece a oferta de alimentos mais saudáveis para o animal e tem como efeito indireto a redução de resíduos químicos no produto. Com a instalação da ordenhadeira mecânica em local adequado ocorre uma melhoria no procedimento de colheita do leite, 
uma vez que, durante o processo, se elimina o contato manual com o animal, ocorrendo a redução de contaminantes biológicos. Associada a isso, a mudança dos procedimentos de pós-colheita, por meio da instalação do resfriador na propriedade, faz com que o produto seja armazenado em temperatura ideal, inibindo o crescimento de microrganismos presentes no leite, melhorando dessa forma a qualidade do produto.

Outro critério positivamente influenciado no aspecto de respeito ao consumidor foi o capital social (índice 3,3), especificamente em relação à integração cultural entre os familiares, com o maior envolvimento de membro da família (esposa) nas atividades da propriedade, o qual passou a adquirir e aplicar conhecimentos sobre as boas práticas tecnológicas adotadas no estabelecimento. Além disso, pelo fato de ser uma UAT, o estabelecimento recebe ações e programas de transferência de tecnologias, como os dias de campo e outros eventos promovidos com parceiros institucionais. Decorrente disso tem ocorrido de forma mais intensa o atendimento a demandas da comunidade local, com a visita de produtores da região do entorno do estabelecimento, os quais se deslocam até a propriedade para observar as práticas ali adotadas.

No aspecto trabalho/emprego (índice $=1,5$ ), destaca-se o critério capacitação (índice $=$ $5,3)$, que registrou contribuições positivas vinculadas à adoção das boas práticas tecnológicas relacionadas à pecuária de leite, por meio da oferta de cursos de curta duração e melhoria no nível básico de capacitação, associada à atualização e absorção de conhecimentos tecnológicos por parte dos responsáveis pelo estabelecimento, com treinamentos que ocorreram na propriedade. Convém ressaltar que esse processo também oportunizou a capacitação de diversos técnicos de extensão rural, habilitando-os a prestar assistência técnica mais qualificada às propriedades que desenvolvem a pecuária leiteira na região. Quanto à qualificação e oferta de trabalho (índice = $0,8)$, observa-se um efeito positivo, porém moderado, decorrente, especificamente, da necessidade de trabalhador braçal com maior nível de especialização para desenvolver as atividades de adubação do pasto, de manejo dos animais nos piquetes e do uso da ordenhadeira mecânica, dentre outros. Além disso, tem ocorrido, eventualmente, a oferta de trabalho para mão de obra temporária, bem como a maior participação de membros da família (esposa) na execução das atividades do estabelecimento. No que tange aos critérios relacionados à qualidade do emprego/ ocupação e à oportunidade, emancipação e equidade de gêneros, gerações e etnias, não foram observadas alterações em seus indicadores.

No aspecto renda (índice $=5,8$ ), a implantação das boas práticas tecnológicas no sistema de produção tem possibilitado a obtenção de ganhos incrementais no faturamento do estabelecimento, refletindo positivamente nos critérios geração de renda (índice $=6,0$ ) e valor da propriedade (índice $=5,5$ ). Em outros termos, atualmente há maior segurança de obtenção de renda, dada a introdução das novas ações no processo produtivo, gerada com estabilidade, pela intensificação produtiva; há melhor distribuição, com salários pagos e recrutamento de pessoal, ainda que temporário, além de grande aumento no montante anual auferido, decorrente do crescimento da produção e melhora no preço do produto em função do resfriamento do leite. Além disso, com a elevação da produção de bezerros, decorrente do aumento da UA/ha, tem-se um ganho extra com a comercialização desses animais, refletindo também no incremento do montante da renda. Adicionalmente a esses efeitos, há a valorização da propriedade, resultante de diversos investimentos em benfeitorias, tais como a recuperação e modernização do curral, a instalação 
da ordenhadeira mecânica e do ponto do resfriador, além da reforma e ampliação do imóvel da sede da fazenda. A instalação do resfriador possibilitou ganhos adicionais ao preço do leite; e a conservação dos recursos naturais, que ocorreu devido à utilização de menor área para produção de pastagem e recuperação do solo, constitui prática que contribui para a conformidade da propriedade com a legislação ambiental, impactando em valor adicionado à propriedade.

No aspecto saúde (índice $=8,1$ ), observam-se alterações positivas no critério segurança e saúde ocupacional (índice $=5,3$ ). As melhorias efetivadas na propriedade, com a instalação do curral com cobertura e piso adequados, reduziram fortemente a exposição das pessoas que ali trabalham ao calor e à umidade. A mudança no padrão de manejo com o pastejo rotacionado também possibilita aos animais que expressem comportamento mais dócil, diminuindo, entre outros fatores, a exposição do trabalhador à periculosidade. A diminuição do uso de herbicidas no pasto reduz a exposição a agentes químicos. Todos esses fatores contribuem para a melhoria das condições de segurança e saúde ocupacional. Por sua vez, o critério segurança alimentar (índice $=11,0$ ) sofreu um efeito altamente positivo, resultado de maior garantia da produção com o processo de intensificação produtiva, que proporciona maior fornecimento de leite para o laticínio e, portanto, oferta de maior quantidade de alimento para o mercado da região. Ademais, há melhoria na qualidade nutricional do leite, decorrente de uma alimentação mais adequada e nutritiva dos animais, com a introdução das forrageiras e suplementação alimentar por meio da silagem de cana-de açúcar e sais minerais.

No aspecto gestão e administração (índice $=4,0$ ), a adoção das boas práticas tecnológicas exerce impactos positivos na propriedade, principalmente nos critérios dedicação e perfil do responsável (índice $=8,3$ ) e condição de comercialização (índice $=6,0$ ). Isso porque o processo de intensificação e complexidade produtiva tem exigido maior capacitação dirigida à atividade por parte do proprietário, o qual tem absorvido conhecimento sobre diversas práticas, como adubação, ordenha, início de pastejo, época de aplicação do calcário, sequência de rotações nos piquetes, entre outras. Esse processo exige um acompanhamento mais acurado dessas atividades, o que tem levado o produtor a permanecer mais tempo no estabelecimento, contando com o efetivo envolvimento da esposa, fortalecendo assim o engajamento familiar nas atividades de gestão da propriedade. Embora as atividades, no estabelecimento, tenham aumentado, o produtor ainda não faz uso de sistema contábil e de modelo formal de planejamento nem possui um sistema de certificação/rotulagem para o seu produto e empreendimento. Em relação às condições de comercialização observam-se efeitos positivos com a venda direta do leite para o laticínio, sendo este o responsável por captar o produto no estabelecimento do produtor. Houve melhoria no processamento e no armazenamento local do produto, com as instalações adequadas do curral, da ordenhadeira e do resfriador. $\mathrm{O}$ fato de haver resfriador na propriedade possibilita a cooperação com outros produtores locais, uma vez que esse equipamento serve como recipiente do leite desses produtores para ser comercializado com o laticínio. Atualmente, o produtor ainda não faz uso de propaganda do seu produto e nem possui marca própria, embora, segundo ele, essas ferramentas sejam importantes para alavancar a venda.

No critério de gestão de insumos químicos (índice $=3,3$ ) houve pequena melhoria nos seus indicadores, com a execução de práticas de calibração e verificação dos equipamentos utilizados, além da devolução dos recipientes e embalagens às lojas veterinárias. Embora ocorra uso parcial 
de equipamentos de proteção individual (EPI), há a necessidade da utilização correta e efetiva para melhor proteção do aplicador, além de se requerer também a devida adequação do armazenamento e registro dos tratamentos dos insumos químicos. No critério disposição de resíduos, não foram observadas alterações, uma vez que não ocorre o tratamento dos resíduos domésticos e da produção na propriedade.

No critério relacionamento institucional $(2,5)$, observam-se impactos positivamente moderados, especificamente quanto à utilização de assistência técnica, por meio de transferência de tecnologia, com a implantação da UAT em parceria com a Embrapa; e à utilização de assessoria legal por ocasião de procedimentos que exigem o enquadramento da propriedade aos ditames legais e normativos, como o Cadastro Ambiental Rural (CAR), o acesso a financiamento, e a obtenção deste, pelo Programa Nacional de Fortalecimento da Agricultura Familiar (Pronaf), entre outros.

\section{Avaliação de desempenho socioambiental}

O índice geral de desempenho das boas práticas tecnológicas relacionadas à pecuária de leite na Fazenda Riacho Grande é positivo, alcançando o valor de 3,55 (Figura 4), em uma escala de $-15 \mathrm{a}+15$, empregada nos procedimentos de ponderação do sistema Ambitec-Agro. A maioria dos critérios analisados revelou efeitos positivos, com exceção dos critérios de consumo de água e energia, os quais tiveram efeitos negativos; além de outros que não sofreram alterações.

Assim, nos critérios que compõem a dimensão de impactos ecológicos, destacam-se a melhoria na qualidade do solo, a redução do uso de insumos veterinários e matérias-primas e de insumos agrícolas, contribuindo para a qualidade ambiental na propriedade. Menciona-se também que o processo de intensificação produtiva, que eleva a produtividade, impacta positivamente no uso direto da terra, embora tenha ocorrido aumento do consumo de água e de energia no estabelecimento.

Na dimensão de impactos socioambientais consideram-se o aspecto respeito ao consumidor, por meio da qualidade do produto e do bem-estar e saúde animal; e o aspecto saúde, sobretudo no tocante à segurança alimentar, os que melhor evidenciaram positivamente o desempenho do estabelecimento. No aspecto renda, os quesitos ligados à geração de renda refletiram em ganhos incrementais com as atividades introduzidas no estabelecimento, além da valorização da propriedade mediante as benfeitorias realizadas e a conservação dos recursos naturais. No aspecto gestão e administração, os quesitos dedicação e perfil do responsável e condição de comercialização se destacaram positivamente, além dos reflexos positivos na gestão dos insumos químicos e no relacionamento institucional, os quais contribuíram para melhorar o desempenho socioambiental da propriedade.

\section{Considerações finais}

Os indicadores de sustentabilidade na UAT Fazenda Riacho Grande, apresentados no presente estudo, apontam que a adoção de boas práticas tecnológicas proporcionou impactos posi- 
tivos nos desempenhos produtivos e socioambientais do empreendimento, dado o contexto da adoção e das limitações de uma propriedade de âmbito familiar.

A intensificação produtiva com a introdução de boas práticas tecnológicas, como a reforma de pastagem, a introdução de forrageiras de melhor performance, o manejo em pastejo rotacionado e outras melhorias, permitiu o aumento da taxa de lotação dos animais bem como a racionalização do uso de insumos agrícolas e veterinários, que se traduziram em ganhos de produtividade e proporcionaram efeitos positivos nos aspectos de eficiência tecnológica e na qualidade ambiental do estabelecimento, que se relacionam ao impacto ecológico.

Os ajustes nos processos produtivos, somados às adequações da infraestrutura, como a construção de curral coberto, com piso pavimentado e brete, a implantação de ordenhadeira mecânica e a instalação de resfriador, foram melhorias que refletiram em aspectos importantes, como a qualidade do leite produzido, o bem-estar e a saúde animal, a elevação da renda da propriedade, além do efeito na segurança alimentar, tanto na garantia quanto na quantidade de alimentos produzidos, resultando em impactos positivos na dimensão socioambiental.

As práticas inovadoras implementadas na UAT de empreendimento familiar, mesmo quando ocorrem limitações e dificuldades, podem significar uma semente de transição para sistemas produtivos mais sustentáveis. A expectativa de adoção em maior escala nos empreendimentos familiares de produção de leite da mesorregião Sudeste Paraense, onde predomina a pecuária extensiva leiteira, poderá provocar um efeito multiplicador para a transformação da realidade socioprodutiva e ambiental, contribuindo para o desenvolvimento local.

A amplitude e consolidação desse cenário, contudo, passa por ações conjugadas e integradas de políticas públicas de crédito, assistência técnica, pesquisa e transferência de tecnologia e de capacitação, parcerias com instituições públicas e privadas, e sobretudo o incentivo da participação de atores locais e produtores com suas capacidades inovativas, experiências e conhecimentos com vistas à transformação efetiva para a sustentabilidade desse importante segmento produtivo.

\section{Referências}

IBGE. Censo Agropecuário 2017. Rio de Janeiro, 2017. Disponível em: https://censos.ibge.gov.br/ agro/2017. Acesso em: 3 fev. 2020.

IBGE. Cidades - 2020. Rio de Janeiro, 2020. Disponível em: https://cidades.ibge.gov.br/brasil/pa/bom-jesus-do-tocantins/panorama. Acesso em: 15 mar. 2021.

IBGE. Geociências. Rio de Janeiro, 2013. Disponível em: https://www.ibge.gov.br/geociencias/downloads-geociencias.html. Acesso em: 28 jun. 2019.

IBGE. Pesquisa da Pecuária Municipal - 2019. Rio de Janeiro, 2019a. Disponível em: https://sidra.ibge. gov.br/pesquisa/ppm/quadros/brasil/2019. Acesso em: 15 mar. 2021.

IBGE. Produção Agrícola Municipal - 2019. Rio de Janeiro, 2019b. Disponível em: https://sidra.ibge. gov.br/pesquisa/pam/tabelas. Acesso em: 15 mar. 2021. 
IBGE. Produção da Extração Vegetal e da Silvicultura - 2019. Rio de Janeiro, 2019c. Disponível em: https://sidra.ibge.gov.br/pesquisa/pevs/quadros/brasil/2019. Acesso em: 15 mar. 2021.

PARÁ. Secretaria de Estado de Meio Ambiente e Sustentabilidade. Imagens do satélite PLANET (2017). Belém, PA, 2017.

RODRIGUES, G. S. Avaliação de impactos socioambientais de tecnologias na Embrapa. Jaguariúna: Embrapa Meio Ambiente, 2015. 41 p. (Embrapa Meio Ambiente. Documentos, 99). Disponível em: http:// www.infoteca.cnptia.embrapa.br/infoteca/bitstream/doc/1020852/4/2015DC01.pdf. Acesso em: 27 fev. 2020 .

RODRIGUES, G. S.; BUSCHINELLI, C. C. de A.; AVILA, A. F. D. An environmental impact assessment system for agricultural research and development II: institutional learning experience at Embrapa. Journal of Technology Management \& Innovation, v. 5, n. 4, p. 38-56, 2010.

RODRIGUES, G. S.; CAMPANHOLA, C.; KITAMURA, P. C. An environmental impact assessment system for agricultural R\&D. Environmental Impact Assessment Review, v. 23, n. 2, p. 219-244, 2003 a.

RODRIGUES, G. S.; CAMPANHOLA, C.; KITAMURA, P. C. Avaliação de impacto ambiental da inovação tecnológica agropecuária: AMBITEC-AGRO. Jaguariúna: Embrapa Meio Ambiente, 2003b. 95 p. (Embrapa Meio Ambiente. Documentos, 34). Disponível em: http://www.cnpma.embrapa.br/download/ documentos_34.pdf. Acesso em: 3 mar. 2020.

RODRIGUES, G. S. et al. Análise de desempenho socioambiental da integração lavoura-pecuária: estudo de caso da Fazenda Elizabeth, Paragominas, estado do Pará, PA. Belém, PA: Embrapa Amazônia Oriental, 2018. 36 p. (Embrapa Amazônia Oriental. Documentos, 438). Disponível em:

https://ainfo.cnptia.embrapa.br/digital/bitstream/item/183086/1/TC-42-17-DOCUMENTOS-438-aINFO. pdf. Acesso em: 3 mar. 2020.

SENA, A. L. S. et al. Demandas tecnológicas para o sistema produtivo da pecuária de leite nas microrregiões de Marabá e de Redenção, Estado do Pará. Belém, PA: Embrapa Amazônia Oriental, 2014. 27 p. (Embrapa Amazônia Oriental. Documentos, 398). Disponível em: https://www.infoteca.cnptia.embrapa.br/bitstream/doc/986042/1/DOC398.pdf. Acesso em: 3 mar. 2020.

SOARES, B. C. et al. Caracterização dos sistemas produtivos de bovinos leiteiros do município de Rondon do Pará, mesorregião Sudeste Paraense. In: SIMPÓSIO DE ESTUDOS E PESQUISAS EM CIÊNCIAS AMBIENTAIS NA AMAZÔNIA, 3., 2014, Belém, PA. Anais... [Belém, PA]: Universidade do Estado do Pará, Centro de Ciências Naturais e Tecnologia, 2014. v. 1, p. 436-442. Disponível em: https://ainfo. cnptia.embrapa.br/digital/bitstream/item/116455/1/p436.pdf. Acesso em: 27 fev. 2020. 